learnt of the plants' magical properties from their most familiar animal. ${ }^{20}$ Whether these mammals deliberately intoxicate themselves is unknown.

Harvesting sustainable plant products, including medicinal plants, can bring poor tropical countries higher economic returns than deforestation. ${ }^{21}$ Increasingly, people are realising that tropical forests are banks with potentially greater long term significance than their financial cousins. The number of possible therapeutic compounds is daunting, but animals may act as signposts, leading to important substances. Animals have practised medicine for millions of years: it would be tragic to lose their potentially lifesaving discoveries.

PAUL NEWTON

Senior house officer

Renal Unit,

Churchill Hospital,

Oxford OX3 7LJ

NATHAN WOLFE Research assistant

Palo Alto Center for Pulmonary Disease Prevention, 750 Welch Rd, Suite 200 .

Palo Alto, CA 94304-1509,

USA
1 Caldecott J. Medicine and the fate of tropical forests. BMF 1987;295:229-30

Reid WV Conserving life's diversity. Environmental Science \& Technology 1992:26:1090-5.

3 Farnsworth NR, Akerele O, Bingel AS, Soejarto DD, Guo Z. Medicinal plants in therapy. Bull World Health Organ 1985;63:965-81.

4 Hollman A. Plants in cardiology. London: BMJ, 1992

5 Freely J. New drugs. London: BMJ, 1991.

6 Janzen D. Complications in interpreting the chemical defenses of trees against tropical arboreal plant-eating vertebrates. In: Montgomery GG, ed. The ecology of arboreal folivores. Washington, DC: Smithsonian Institution, 1978:73-84.

Newton P. The use of medicinal plants by primates: a missing link? Trends in Ecology and Evolution 1991;6:297-9.

8 Sears C. The chimpanzee's medicine chest. New Scientist 1990 Aug 4:42-4

9 Carper ER, Dobson AP. What else can green monkeys tell us about AIDS? Trends in Ecology and Evolution 1987;2:374-6.

10 Phillips-Conroy JE. Baboons, diet and disease: food selection and schistosomiasis. In: Taub DM King FA, eds. Current perspective in primate social dynamics. New York: Van Nostrand Reinhol 1986:287-304.

11 Wrangham R, Nishida T. Aspilia spp leaves-a puzzle in the feeding behaviour of wild chimp: Primates 1983;24:276-82.

12 Newton P, Nishida T. Possible buccal administration of herbal drugs by wild chimpanzees ( $\mathrm{Pa}$ (roglodytes). Animal Behaviour 1990;139:799-800.

13 Rodriguez E, Areguillin $M$, Nishida T, Uehara S, Wrangham R, Abramowski $Z$, et a Thiarubrine A, a bioactive constituent of Aspilia (Asteracea) consumed by wild chimpanzees. Experienta 1985;41:419-20.

14 Grisanzio JA. Fur-bearing pharmacists. Animals 1992;Sept/Oct: 26-30

5 Fauth PT. Ectoparasitism and the role of green nesting material in the European starling. Oecologia 1988;88:22-9.

16 Huffman $M$, Seifu $M$. Observations on the illness and consumption of a possible medicinal plan? Vernonia amygdalina by a wild chimpanzee in Mount Mahale National Park. Primate 1989;30:51-63.

17 Lewin R. What monkeys chew to choose their children's sex. New Scientist 1992 Feb 22:15. 18 Eberhard IH. Ecology of the koala, Phascolarctos cinereus, in Australia. In: Montgomery GG, ed The ecology of arboreal herbivores. Washington, DC: Smithsonian Institution, 1978:315-27.

19 Brander AAD. Wild animals in central India. London: Edward Arnold, 1931

20 Phillips R. Mushrooms and other fungi of Great Britain and Europe. London: Pan, 1981

21 Prance G. Fruits of the rainforest. New Scientist 1990;125:42-5.

\title{
Ghosts, visions, and voices
}

\section{Sometimes simply perceptual mistakes}

\author{
The ghost sat down on the opposite side of the fireplace, as if he were \\ quite used to it. \\ "You don't believe in me," observed the Ghost. \\ "I don't," said Scrooge. \\ "What evidence would you have of my reality, beyond that of your \\ senses?" \\ "I don't know," said Scrooge. \\ "Why do you doubt your senses?" \\ "Because," said Scrooge, "a little thing affects them. A slight \\ disorder of the stomach makes them cheats. You may be an \\ undigested bit of beef, a blot of mustard, a crumb of cheese, a \\ fragment of an underdone potato. There's more of gravy than of grave \\ about you, whatever you are!"’
}

Hallucinations are not always pathological. Hearing one's name called aloud or hearing a person's voice but finding no one there is common. ${ }^{23} \mathrm{~A}$ few people describe hearing a comforting or advising voice at some time in their lives. ${ }^{2}$ Recently bereaved widows and widowers may "hear" or, more commonly, "see" their dead spouse. ${ }^{45}$ Up to one in six people in Britain and the United States have seen, heard, or otherwise experienced ghosts or spirits. ${ }^{6-8}$ Lights, visions, and voices may be seen or heard during profound religious or mystical experiences, especially conversion ${ }^{9}-$ the experiences of Joan of Arc and St Paul are familiar examples. ${ }^{10}$

Every culture has an explanation for voices and visions. For example, Islam understands all such experiences, including visions of saints and angels, clairvoyance, clairaudience, and out of body experiences, in terms of jinn (demons) deceiving humans. " Although psychiatrists would describe these experiences as hallucinations - that is, thoughts or images that the subject mistakenly attributes to an external reference - can they really be understood in terms of psychiatric syndromes?

As such experiences are transient and isolated, major psychiatric illness is unlikely. An overloaded digestive system - on which the unreformed Scrooge based his scepticism about the evidence of his senses and which the lone yachtsman
Slocombe blamed for the sight of an apparition after dining on plums and cheese ${ }^{12}-$ is perhaps insufficient cause for more than a bad dream. But a transient psychosis induced by vitamin deficiency from fasting could cause brief hallucina tions. ${ }^{13}$ Religious and mystical visions could also arise from transient psychosis induced by pain or infection, perhap $\mathbb{Q}$ after self flagellation. ${ }^{13}$ Prolonged vigils may cause the illusions and hypnagogic hallucinations of profound sleep ${ }^{3}$ deprivation. ${ }^{14}$ Prolonged introspection may cause dissociative illusions and hallucinations. ${ }^{15}$ Cerebral dysfunction from any cause, including past head injury, ${ }^{16}$ may promote psychie experiences.

Ghosts that appear at night may be illusions-that is misinterpretations of real objects. Mistakes and misinterpre tations are easily made when there is little sensory stimula tion. "The yard was so dark that even Scrooge, who knew it\$ every stone, was fain to grope with his hands . . . Scrooge ${ }_{N}^{J}$ having his key in the door of the lock, saw in the knocker without its undergoing any intermediate process of change not a knocker, but Marley's face."

Ghosts may also arise from hypnagogic and hypnopompi\&్ hallucinations - that is, normal phenomena of "waking dreams," which occur during the period of clouded con sciousness that accompanies falling asleep and waking up. (A Scrooge woke his Ghost of Christmas Yet To Come "shrank, ? collapsed and dwindled down into a bedpost.") Seeing figureș or hearing music, chimes, or one's own name is a commorf experience. ${ }^{17}$

Hearing one's name called aloud may be a hypnagogic of hypnopompic hallucination or a misinterpretation of another sound. We have a low threshold for hearing our name an 8 therefore a strong tendency to misinterpret ambiguous souns as our name. But some people describe having this experience in clear consciousness, in silence. What may be happening here is that they mistakenly identify a very quiet sound, which would ordinarily be subliminal, for their name. 
Severe stress may precipitate transient, complex hallucinations, which the subject recognises as arising from his or her imagination. ${ }^{18} 19$ Dissociative (conversion) phenomena may account both for these pseudohallucinations and for many spiritual and paranormal phenomena.$^{820} \mathrm{~A}$ dissociative mechanism may also underlie memory flashbacks (which may be experienced as real $^{21}$ ) in post-traumatic stress disorder. ${ }^{22}$ Dissociative experiences may even be normal. ${ }^{8}$

Isolated hallucinations may be common and normal perceptual errors and no more indicative of psychiatric illness than isolated illusions. But, whether we describe visions and voices as psychotic, dissociative, hypnagogic, or normal, uncertainties remain about their underlying psychophysiology and the relations between these seemingly very different states of mind.

FRANCES KLEMPERER

Senior Registrar in General Psychiatry,

Bexley Hospital,

Bexley DA5 2BW
2 Posey TB, Losch ME. Auditory hallucinations of hearing voices in 375 normal subjects. Imagination, Cognition and Personality 1983-4;3:99-113.

Bentall RP, Slade P. Reliability of a scale measuring predisposition towards hallucination: a brief report. Fourmal of Personality and Individual Differences 1985;6:527-9.

Parkes CM. Bereavement and mental illness. Br F Med Psychol 1965;38:1-25.

Rees WD. The hallucinations of widowhood. BM7 1971;iv:37-41.

6 Sidgewick HA. Report of the census of hallucinations. Proceedings of the Society for Psychical Research, 1894:26:259-394.

West DJ. A mass

questionnaire on hallucinations. Fournal of the Society for Psychical Research, 1948:10:25-402.

8 Ross CA, Joshi S. Paranormal experiences in the general population. $f$ Nerv Ment Dis 1992;180:357-61.

9 James W. The varieties of religious experience. New York: Modern Library, 1902.

10 Holy Bible. Acts ix, 3-4.

11 Taymeeyah I. The jinn. Riyadh: Tawheed Publications, 1989. (Trans. Abu Ameenah Bilab Philips!

12 Slocombe J. Sailing alone around the world. London: Reprint Society, 1900.

13 Huxley A. Heaven and hell. New York: Perrenial Library, 1955.

14 Shaw G, Crossland J. Hallucinogenic drugs and altered states of consciousness. In: Underwood G, Stevens R, eds. Aspects of consciousness. Vol 2. London: Academic Press, 1981:185.

5 Waddington D. Socrates' symptom. Br f Psychiatry 1992;161:424-5.

16 Fenwick P, Galliano S, Coate MA, Rippere V, Brown D. Psychic sensitivity, mystical experience, head injury and brain pathology. Br $\mathcal{F}$ Med Psychol 1985:58:35-44.

Schacter DL. The hypnagogic state: a critical review of the literature. Psychol Bull 1976;83:452-81.

8 Goldstein AG. Hallucinatory experience: a personal account f A hnorm Psychol 1976:85:423-9.

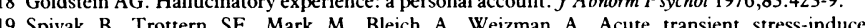

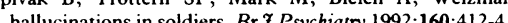

Wallace AFC. Stress and personality change. International Record of Medicine and General Practice Clinics 1956;169:12.

Clinics 1956;169:12.
Mueser KT, Butler RW. Auditory hallucinations in combat-related chronic posttraumatic stress Mueser KT, Butler RW. Auditory hallucinations
disorder. Am f Psychiatry 1987;144:299-302.

22 McGee R. Flashbacks and memory phenomena. F Nerv Ment Dis 1984;172:273-8.

\section{Geoffrey Rose's big idea}

\section{Changing the population distribution of a risk factor is better than targeting people at high risk}

We are all responsible for all. (Dostoevsky)

Few people have the greatness of heart and mind to be moved by mere statistics, and Geoffrey Rose, who recently retired from the chair of epidemiology at the London School of Hygiene and Tropical Medicine, is one of them. His valedictory book, The Strategy of Preventive Medicine, ${ }^{1}$ is written in an epidemiological tradition that goes back to the central ideas of the sanitary physicians of the previous century: the "patient" of preventive medicine is "the population," and its health is measured by statistics. Preventive measures aim to improve these statistics. The first quotation in the book comes from Virchow, reflecting on the link between the history of diseases and the history of human culture. The last sentence of the book echoes another Virchovian thought, that "medicine and politics cannot and should not be kept apart."

The book follows a crisp train of thought. It starts characteristically with Rose's rationale for prevention: "It is better to be healthy than ill or dead. That is the beginning and the end of the only real argument for preventive medicine. It is sufficient." Pivotal in Rose's argument is the "PlattPickering" controversy; he admits that "Pickering may have won the battle but lost the war." Sir George Pickering was the first to express the view that a sharp distinction between hypertension and normotension is a medical artefact. ${ }^{2} \mathrm{He}$ proposed that hypertension is a quantitative rather than a qualitative phenomenon. Rose maintains that Pickering failed to see the wider implications of his concept. Not only is it hard to tell where hypertension starts when you study the distribution of blood pressure within a population but it is equally hard to tell where dementia or osteoporosis begins when you study cognitive function or bone mineral density.

In addition, a risk factor usually gradually rather than abruptly increases the risk of disease. For example, the frequency of coronary heart disease rises gradually with blood pressure, with no sharp delineation of hypertensive and normotensive subjects. The presence of most people in the middle of the distribution of blood pressure implies that most patients with heart disease in whom raised blood pressure is a factor will have only moderately raised blood pressures. More clinical cases result from small but widespread risks than large but rare risks.

This leads to what Rose has coined the "prevention paradox": preventive actions that greatly benefit the population at large may bring only small benefits for individual people. This is the central issue in comparing the merits of the two main preventive strategies: the high risk approach and the population approach. The high risk approach aims to detect people at high risk of disease and lower their risk by treatment. The population strategy aims to shift the whole distribution of a risk factor in a favourable direction. Comparison of the two strategies suggests, in Rose's words, that "preventive medicine must embrace both, but, of the two, power resides with the population strategy." Thereby, Rose places himself squarely in a tradition that expects more from the population approach than from clinical medicine.

The implications are considerable. Much of the loss of life below the age of 65 results from potentially preventable diseases and events such as cardiovascular diseases, various types of cancer, accidents, and suicide. Rose does not treat these diseases systematically but discusses many quantitatively and qualitatively important conditions. There is some emphasis on coronary heart disease, the subject in which Rose first presented his views on the competing high risk and population strategies, but also on osteoporosis and fractures, Down's syndrome, and mental illnesses.

A problem is the general lack of data to support his view that preventive measures directed towards the whole population. will not only in theory but also in practice prevent disease. Rose is, of course, not to blame for this. On the contrary, he has been at the cradle of many studies that have accumulated knowledge about prevention. Still, his book is, perhaps necessarily so, largely based on circumstantial evidence.

The main question is whether a shift of the population distribution does indeed alter the risk. Part of the population may already be at so low a risk of a particular disease that manipulating the distribution of risk factors within the whole 